\title{
The Simultaneous Determination of Silicic, Boric and Carbonic Acids in Natural Water via Ion-Exclusion Chromatography with a Charged Aerosol Detector
}

\author{
Yu Otsuka ${ }^{1, \dagger}$, Nobutake Nakatani ${ }^{1, *}$, Takuya Takahashi ${ }^{1}$, Daisuke Kozaki ${ }^{2}$, Masanobu Mori ${ }^{3}$ \\ and Kazuhiko Tanaka ${ }^{4}$ \\ 1 Department of Environmental and Symbiotic Science, College of Agriculture, Food and Environmental \\ Sciences, Rakuno Gakuen University, 582 Bunkyodai-Midorimachi, Ebetsu, Hokkaido 069-8501, Japan; \\ y_outsuka214@eis.hokudai.ac.jp (Y.O.); t.takahashi11290809@gmail.com (T.T.) \\ 2 Faculty of Industrial Sciences and Technology, University Malaysia Pahang, \\ Lebuhraya Tun Razak 26300 Gambang Kuantan, Pahang Darul Makmur, Malaysia; \\ emerald.green.2-10@hotmail.co.jp \\ 3 Graduate School of Engineering, Gunma University, 1-5-1 Tenjin-cho, Kiryu, Gunma 376-8515, Japan; \\ mori@gunma-u.ac.jp \\ 4 Faculty of Engineering, Chubu University, 1200 Matsumoto-cho, Kasugai, Aich 487-8501, Japan; \\ tanakaic-ky@ked.biglobe.ne.jp \\ * Correspondence: nakatani@rakuno.ac.jp; Tel.: +81-11-388-4714; Fax: +81-11-388-4714 \\ + Current address: Graduate School of Environmental Science, Faculty of Environmental Earth Science, \\ Hokkiado University, N10W5, Sapporo, Hokkaido 060-0810, Japan
}

Academic Editor: Christopher R. Harrison

Received: 14 January 2016; Accepted: 26 February 2016; Published: 8 March 2016

\begin{abstract}
The simple and simultaneous determination of silicic, boric and carbonic acids was made using ion-exclusion chromatography (IEC) and a Corona ${ }^{\mathrm{TM}}$ charged aerosol detector (C-CAD). Silicic and boric acids were separated by the column packed with a weakly acidic cation-exchange resin in $\mathrm{H}^{+}$-form and ultra-pure water eluent, and the detector responses were improved by the addition of acetonitrile to eluent. Under the optimized conditions, the simultaneous determination of weak inorganic acids, except for carbonic acid, was successfully performed. When the conversion column packed with a strong acidic cation-exchange resin in $\mathrm{Na}^{+}$- or $\mathrm{K}^{+}$-form was inserted between the separation column and the detector, weak inorganic acids including carbonic acid could be detected by the C-CAD. The calibration curves were linear in the range of $0.5-10 \mathrm{mg} \cdot \mathrm{L}^{-1}$ as $\mathrm{Si}$ for silicic acid $\left(r^{2}=0.996\right), 10-100 \mathrm{mg} \cdot \mathrm{L}^{-1}$ as $\mathrm{B}$ for boric acid $\left(r^{2}=0.998\right)$ and $1.3-21 \mathrm{mg} \cdot \mathrm{L}^{-1}$ as $\mathrm{C}$ for carbonic acid $\left(r^{2}=0.993\right)$. The detection limits based on three times the standard deviation were $0.03 \mathrm{mg} \cdot \mathrm{L}^{-1}$ as $\mathrm{Si}$ for silicic acid, $0.40 \mathrm{mg} \cdot \mathrm{L}^{-1}$ as B for boric acid and $0.08 \mathrm{mg} \cdot \mathrm{L}^{-1}$ as $\mathrm{C}$ for carbonic acid. This method was applicable to river, hot spring and drinking water.
\end{abstract}

Keywords: ion-exclusion chromatography (IEC); Corona ${ }^{\mathrm{TM}}$ charged aerosol detector (C-CAD); silicic acid; boric acid; carbonic acid; conversion column

\section{Introduction}

Silicon, boron and carbon are ubiquitously present in the natural environment. These elements play important roles in geochemical and biological cycles. For example, silicon dioxide, one of the chemical form of silicon, is the most abundant component of the earth's crust and undergo physical and chemical weathering. The dissolved silicon by the weathering is transported via rivers to the oceans, where it is taken up biologically to form carbonate and biogenic silica in the tissues and skeletons of plankton [1]. On the other hand, silica is a fundamental constituent of a wide range of 
ceramic products, glasses, abrasives, refractory materials, fillers in paints and optical components [2]. Boron [3] and carbon [4] are also the components of earth's crust and are known to play important roles in the natural geochemical cycles as well as in industry. In the aquatic environment, the dissolved chemical forms of silicon, boron and carbon are mainly silicic, boric and carbonic acids, which are oxide forms. These dissolved chemicals are classified in terms of weak inorganic acids, because the logarithmic dissociation constants of silicic $\left(\mathrm{p} K_{\mathrm{a} 1}=9.5, \mathrm{p} K_{\mathrm{a} 2}=12.6\right)$, boric $\left(\mathrm{p} K_{\mathrm{a}}=9.3\right)$ and carbonic acids $\left(\mathrm{p} K_{\mathrm{a} 1}=6.3, \mathrm{p} K_{\mathrm{a} 2}=10.3\right)$ [5] are around or more than 6 . Therefore, they are present in partially dissociated or un-dissociated forms in natural water displaying a neutral $\mathrm{pH}$.

The determinations of these acids in natural water have been individually performed by the spectrophotometry based on the specific chemical derivatization with molybdate for silicic acid and with curcumin or carmine for boric acid, and by the neutralization titration method for carbonic acid [6]. Inductively coupled plasma atomic emission spectroscopy (ICP-AES) and inductively coupled plasma mass spectroscopy (ICP-MS) are also useful methods for the determination of silicic and boric acids $[7,8]$.

Ion chromatography (IC) is known to be powerful method for the separation and determination of ionic species simultaneously, and ion-exclusion chromatography (IEC) is a very useful technique for separating relatively small weak acids [9]. While the IEC with a conductivity detector was a simple analytical system for the determination of silicic [10], boric [11] and carbonic [12] acids, the IEC with spectrophotometric detection was preferred due to the low conductimetric sensitivity depending on the limiting equivalent ionic conductance. The post-column derivatization by using molybdate for silicic acid [13-15] and azomethine $\mathrm{H}$ for boric acid [16] following the separation using IEC had been applied to improve the analytical sensitivity. However, these analytical systems were complicated by requiring an additional pump for chromogenic reagent, and none of them were for simultaneous multicomponent determination of silicic, boric and carbonic acids.

Recently, a charged aerosol detector (CAD) has been developed as a universal and aerosol-based detector for high performance liquid chromatography (HPLC) [17-19]. This detector is used for the detection of poor UV chromophores and non- and semi-volatile compounds including amino acids antibiotics, carbohydrates, fatty acids, hormones, lipid pharmaceuticals, phospholipids, surfactants and steroids [20]. For cations and anions as pharmaceutical counterions, zwitterionic chromatography [21], hydrophilic interaction chromatography [22] and mixed-mode chromatography [23] with a CAD had already been developed. In our previously study, the selective separation and sensitive detection of dissolved silicon and boron in aqueous phase using an IEC and a Corona ${ }^{\mathrm{TM}}$ CAD (C-CAD) was developed by combining an electrodialysis ion isolation device (EID) as a salt remover [24]. Although this method is effective for the simultaneous determination of dissolved silicon and boron in highly salty water such as seawater and hot spring water without derivatization reaction, the EID system was specially hand-made and intricate in construction.

The purpose of this study was to achieve a simple and the simultaneous determination of silicic, boric and carbonic acid in natural water by using IEC and the C-CAD. The separation column used in this study was developed for the simultaneous determination of common anions and cations that are separated by ion-exclusion and cation-exchange mechanisms, respectively [25-27]. Silicic and boric acids could be separated from strong acid anions through the separation column and be detected by the C-CAD, but carbonic acid could not be detected. Using the conversion column packed with strongly acidic cation-exchange resin in $\mathrm{Na}^{+}-$or $\mathrm{K}^{+}$-form, the simultaneous determination of silicic, boric and carbonic acids has been accomplished by IEC and the C-CAD.

\section{Materials and Methods}

\subsection{Chemicals and Reagents}

All reagent-grade or analytical-grade chemicals used in this study were purchased from Wako Pure Chemical Industries Ltd. (Osaka, Japan). Commercial standard solutions of phosphoric 
(1000 mg $\cdot \mathrm{L}^{-1}$ as $\mathrm{P}, \mathrm{KH}_{2} \mathrm{PO}_{3}$ in water), silicic (1000 mg $\cdot \mathrm{L}^{-1}$ as $\mathrm{Si}, \mathrm{Na}_{2} \mathrm{SiO}_{3}$ in $0.2 \mathrm{~mol} \cdot \mathrm{L}^{-1} \mathrm{Na}_{2} \mathrm{CO}_{3}$ ) and boric (1000 mg. $\mathrm{L}^{-1}$ as $\mathrm{B}, \mathrm{H}_{3} \mathrm{BO}_{3}$ in water) acids were used as a stock standard solution. The concentration of carbonic acid dissolving in the standard solution of silicic acid was determined by other ion chromatographic method [12] using the diluted standard solution of sodium bicarbonate (1000 $\mathrm{mg} \cdot \mathrm{L}^{-1}$ as $\mathrm{C}, \mathrm{Na}_{2} \mathrm{CO}_{3}$ in water). Ultra-pure water (>18 M $\Omega \cdot \mathrm{cm}$, Organo Co., Suwa, Japan) was used as an eluent and for the preparation of the standard solution and the reagent.

\subsection{Apparatus}

The ion chromatograph system consisted of dual pump (DP-8020, Tosoh Co. Ltd., Tokyo, Japan), on-line degasser (SD-8022, Tosoh Co. Ltd., Tokyo, Japan), column oven (CO-8020, Tosoh Co. Ltd., Tokyo, Japan) and a Corona ${ }^{\mathrm{TM}}$ charged aerosol detector (Corona ${ }^{\mathrm{TM}}$ CAD, ESA Biosciences Co., Chelmsford, MA, USA). Operating conditions of the C-CAD were as follows: $\mathrm{N}_{2}$ gas flow rate, $1.53 \mathrm{~L} \cdot \mathrm{min}^{-1} ; \mathrm{N}_{2}$ gas flow ratio, 0.46 ; corona voltage, $2.31 \mathrm{kV}$; corona current, $1.0 \mu \mathrm{A}$; ion trapping voltage, $20.3 \mathrm{~V}$; and gas pressure $35 \mathrm{psi}$. These apparatuses, except for the detector, were controlled, and the detector signal was collected with a chromatographic workstation (LC-8020 Model-II, Tosoh Co. Ltd., Tokyo, Japan). The injector was a manual six-way valve equipped with a $100 \mu \mathrm{L}$ sample loop. The typical flow rates of the eluent were $0.6 \mathrm{~mL} \cdot \mathrm{min}^{-1}$. Purified $\mathrm{N}_{2}$ gas $(99.999 \%)$ was used for the C-CAD. The column oven temperature was set at $45^{\circ} \mathrm{C}$.

\subsection{Columns}

The separation column used in this study was a Tosoh TSKgel Super IC-A/C $(150 \mathrm{~mm}$ length $\times 6.0 \mathrm{~mm}$ i.d.) packed with a polymethacrylate-based weakly acidic cation-exchange resin ( 0.2 mequivalent $\mathrm{mL}^{-1}$ cation exchange capacity). This column was conditioned by passing through $20 \mathrm{~mL}$ of $100 \mathrm{mmol} \cdot \mathrm{L}^{-1} \mathrm{H}_{2} \mathrm{SO}_{4}$ solution to a cation-exchange resin in the $\mathrm{H}^{+}$-form. A conversion column ( $35 \mathrm{~mm}$ length $\times 4.0 \mathrm{~mm}$ i.d.) for counter ions of analytes used in this study was packed with a polystyrene-divinylbenzene-based strongly acidic cation-exchange resin ( $5 \mu \mathrm{m}$ particle size, 1.5 mequivalent $\mathrm{mL}^{-1}$ cation exchange capacity) of TSKgel SCX (Tosoh Co. Ltd., Tokyo, Japan) via the slurry technique. This column was conditioned by passing through at least $20 \mathrm{~mL}$ of a $100-\mathrm{mmol} \cdot \mathrm{L}^{-1}$ $\mathrm{NaCl}$ or $\mathrm{KCl}$ solution to a strongly acidic cation-exchange resin in $\mathrm{Na}^{+}-$or $\mathrm{K}^{+}$-form. These column were kept in the column oven and were equilibrated with eluent for $1 \mathrm{~h}$ before chromatographic runs.

\subsection{Natural Water Samples}

River and hot spring water samples were collected within Hokkaido, Japan. The temperature of the hot spring water was $43^{\circ} \mathrm{C}$. Commercial drinking water samples in polyethylene terephthalate (PET) bottles were purchased from a market store. These water samples were filtered through a cellulose acetate syringe filter with $0.45-\mu \mathrm{m}$ pore size $\left(\right.$ Minisart ${ }^{\circledR}$, Sartorius Stedim Biotech $\mathrm{GmbH}$, Göttingen, Germany) and were stored in the dark at $4{ }^{\circ} \mathrm{C}$ until analysis.

\section{Results}

\subsection{Ion-Exclusion Chromatography with the C-CAD of Weak Inorganic Acids with a Water Eluent}

To optimize the analytical conditions for the separation and detection of weak inorganic acids, the retention behavior and detector responses were examined by using ultra-pure water as an eluent. The retention times of weak inorganic acids decreased gradually on increasing the eluent flow rate ranging from 0.2 to $1.0 \mathrm{~mL} \cdot \mathrm{min}^{-1}$, and the elution order was phosphoric acid, silicic acid and boric acid (Figure 1), while the peak of carbonic acid could not observed for at least $30 \mathrm{~min}$ in any case. Additionally, the detector response of these acids remained unchanged. The separation of weak acids by ion-exclusion chromatography on cation-exchange column mainly depended on the $\mathrm{p} K_{\mathrm{a} 1}$ values of acids in the ranges 1.3-6.4 [28]. The dominant proportion of phosphoric acid is dihydrogen phosphate ion $\left(\mathrm{H}_{2} \mathrm{PO}_{4}{ }^{-}\right)$and hydrogen phosphate ion $\left(\mathrm{HPO}_{4}{ }^{2-}\right)$ in water eluent, showing that these ions were 
almost completely ion-excluded. While both acids would be present as un-dissociated forms in water eluent and fully penetrate to the liquid within the resin, the elution of the silicic acid was faster than that of boric acid. In addition to liquid partition, it has been suggested that other mechanisms such as hydrophobic adsorption, screening effect, solute effective charge, resin structure and number of functional group [29] have an influence on the retention of weak inorganic acids. Although the attraction of weak inorganic acids to the stationary phase could be affected by the hydrophobic adsorption of common inorganic acids on resin, which are well-known as a side-effect in the separation by IEC with a polymeric resin [30,31], the detailed mechanism will be the subject of future work. In the separation column packed with cation-exchange resin in $\mathrm{H}^{+}$-form, the anions were converted to the corresponding acid [9]. Because carbonic acid molecular formed in the separation column would be decomposed into carbon dioxide and water in the drying tube of the C-CAD, carbonate ion could not be detected. Other anions would transforms the liquid phase into small droplets in the drying tube and be detected. While silicic and boric acids could be completely separated for any case of flow rate in this study, those in some natural water could not be separated from the strong acid anions (i.e., $\mathrm{SO}_{4}{ }^{2-}$, $\mathrm{Cl}^{-}$and $\mathrm{NO}_{3}{ }^{-}$) at higher flow rate of eluent. In terms of adequate separation and time-consuming, the optimized flow rate was set at $0.6 \mathrm{~mL} \cdot \mathrm{min}^{-1}$ in this study.

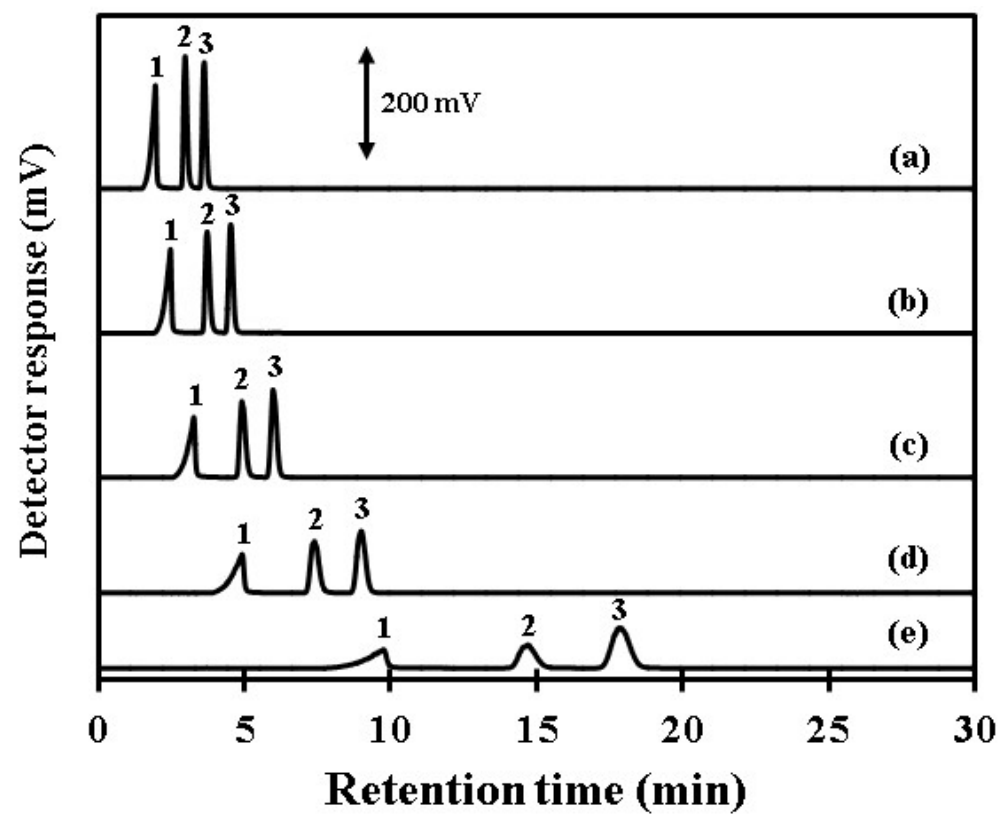

Figure 1. Chromatograms of four weak inorganic acids with eluent flow rate at (a) $1.0 \mathrm{~mL} \cdot \mathrm{min}^{-1}$; (b) $0.8 \mathrm{~mL} \cdot \mathrm{min}^{-1}$; (c) $0.6 \mathrm{~mL} \cdot \mathrm{min}^{-1}$; (d) $0.4 \mathrm{~mL} \cdot \mathrm{min}^{-1}$ and (e) $0.2 \mathrm{~mL} \cdot \mathrm{min}^{-1}$. Conditions: separation column, polymethacrylate-based weakly acidic cation-exchange resin column TSKgel Super IC-A/C (150 mm length $\times 6.0 \mathrm{~mm}$ i.d.); eluent, ultra pure water; injected sample, a mixture solution of $10 \mathrm{mgP} \cdot \mathrm{L}^{-1}, 10 \mathrm{mgSi} \cdot \mathrm{L}^{-1}, 100 \mathrm{mgB} \cdot \mathrm{L}^{-1}$ and $21 \mathrm{mgC} \cdot \mathrm{L}^{-1}$; injected volume, $100 \mu \mathrm{L}$; column temperature, $45^{\circ} \mathrm{C}$. Peaks identification: 1, phosphoric acid; 2, silicic acid; 3, boric acid.

\subsection{Effect of Acetonitrile Addition to a Water Eluent on the Detector Response of Weak Inorganic Acids}

The volatility of the mobile phase have an effect on the detector response of compound due to the improvement of droplet formation within the nebulizer spray chambers system and of mobile phase evaporation in the drying tube [19]. In this study, $5 \%-20 \%$ of acetonitrile in the eluent were examined, because more than $20 \%$ of acetonitrile have a bad influence on the column robustness, as suggested by Tosoh Corporation. Increasing the percentage of acetonitrile in water mobile phase significantly increased the detector response of analytes where the retention times of all analytes were almost unchanged (Figure 2). In the following experiment, the concentration of acetonitrile in the 
eluent was set to $15 \%$ in order to increase column robustness. Finally, the detector responses could be improved 2.1-fold for phosphoric acid, 2.3-fold for silicic acid and 1.4-fold for boric acid by the addition of acetonitrile to a water eluent.

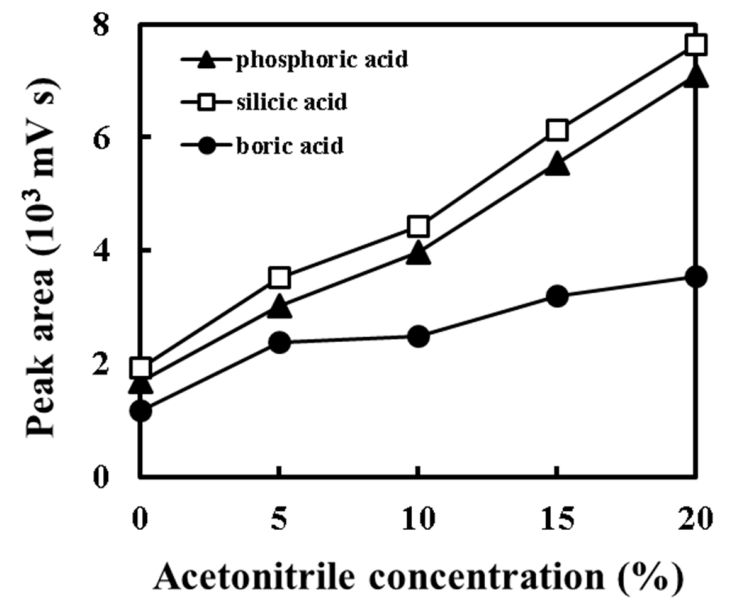

Figure 2. Effect of acetonitrile concentration in the eluent on the detector responses for phosphoric, silicic and boric acids. Conditions: flow rate of eluent, $0.6 \mathrm{~mL} \cdot \mathrm{min}^{-1}$. Other conditions are the same as in Figure 1.

Under the optimized separation and detection conditions, the typical chromatogram was shown in Figure 3. The separation of silicic and boric acids from strong acid anions of $\mathrm{Br}^{-}, \mathrm{I}^{-}, \mathrm{NO}_{3}{ }^{-}, \mathrm{SO}_{4}{ }^{2-}$ and $\mathrm{Cl}^{-}$present in natural waters were successfully performed by IEC with the C-CAD. However, the peaks of strong acid anions, which might be almost completely ion-excluded in the weakly acidic column, were overlapped with that of phosphoric acid. Therefore, the concentration of phosphoric acid in natural waters could not be determined in this study.

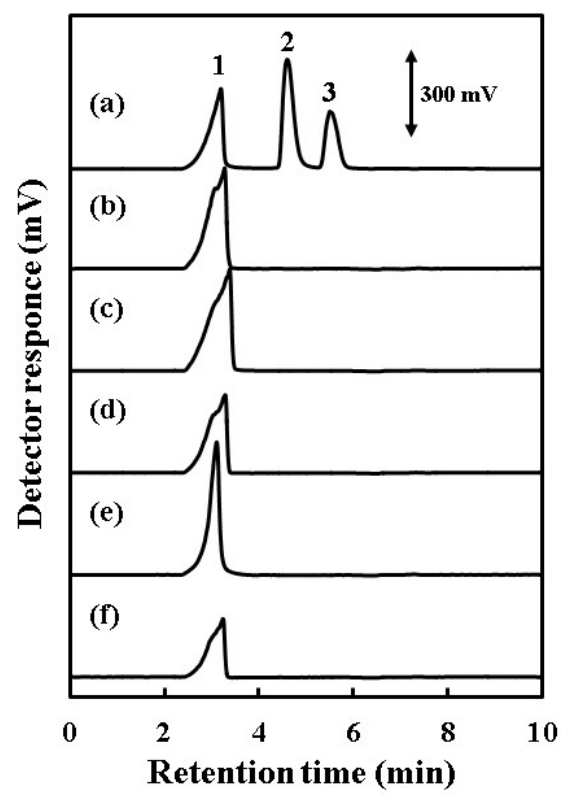

Figure 3. Typical chromatograms of (a) a mixture standard solution of phosphoric, silicic, boric and carbonic acids, and the solution of (b) $1 \mathrm{mmol} \cdot \mathrm{L}^{-1} \mathrm{NaBr}$, (c) $1 \mathrm{mmol} \cdot \mathrm{L}^{-1} \mathrm{KI}$, (d) $1 \mathrm{mmol} \cdot \mathrm{L}^{-1} \mathrm{KNO}_{3}$, (e) $0.5 \mathrm{mmol} \cdot \mathrm{L}^{-1} \mathrm{Na}_{2} \mathrm{SO}_{4}$ and (f) $1 \mathrm{mmol} \cdot \mathrm{L}^{-1} \mathrm{NaCl}$ under the optimized analytical conditions. Other chromatographic conditions are the same as for Figure 2. Peak identification: 1 strong acid anions $\left(\mathrm{Br}^{-}, \mathrm{I}^{-}, \mathrm{NO}_{3}{ }^{-}, \mathrm{SO}_{4}{ }^{2-}\right.$ and $\left.\mathrm{Cl}^{-}\right)$and phosphoric acid; 2, silicic acid; 3, boric acid. 


\subsection{Effect of Conversion Column for Simultaneous Determination of Silicic, Boric and Carbonic Acids}

It was previously pointed out that carbonic acid converted in the separation column packed with cation-exchange resin in $\mathrm{H}^{+}$-form would be decomposed into carbon dioxide and water in the drying tube of the C-CAD. To detect the carbonic acid using the C-CAD after separating by IEC, the conversion column packed with a strong acidic cation-exchange resin (TSKgel SCX) in $\mathrm{Na}^{+}$- or $\mathrm{K}^{+}$-form was applied. The enhancement of conductivity or UV detection for weak inorganic and organic ions had been performed through the use of post-column ion-exchange reactions [12,32-35]. Although carbonic acid could not be detected by using the conversion column in $\mathrm{H}^{+}$-form, the weak inorganic acids including carbonic acid were detected by using the conversion column in $\mathrm{Na}^{+}$- or $\mathrm{K}^{+}$-form after the elution of silicic and boric acids (Figure 4). A strong acidic cation-exchange column in $\mathrm{Na}^{+}$- or $\mathrm{K}^{+}$-form can convert carbonic acid as partially ionized form into sodium $\left(\mathrm{NaHCO}_{3}\right)$ or potassium $\left(\mathrm{KHCO}_{3}\right)$ salt [12,34]. Passing through the drying tube, the salt particles of $\mathrm{NaHCO}_{3}$ or $\mathrm{KHCO}_{3}$ might be formed, and the charged particles could then be detected by the C-CAD. It was recognized that the carbonic acid spends a significant amount of time residing on the surface of the polymetric resin [36], resulting in the longer retention of carbonic acid than those of silicic and boric acid. Because there were no differences in the retention time and detector response of weak inorganic acids using the conversion columns between $\mathrm{Na}^{+}$- and $\mathrm{K}^{+}$-form, the column in $\mathrm{K}^{+}$-form was used in this study.

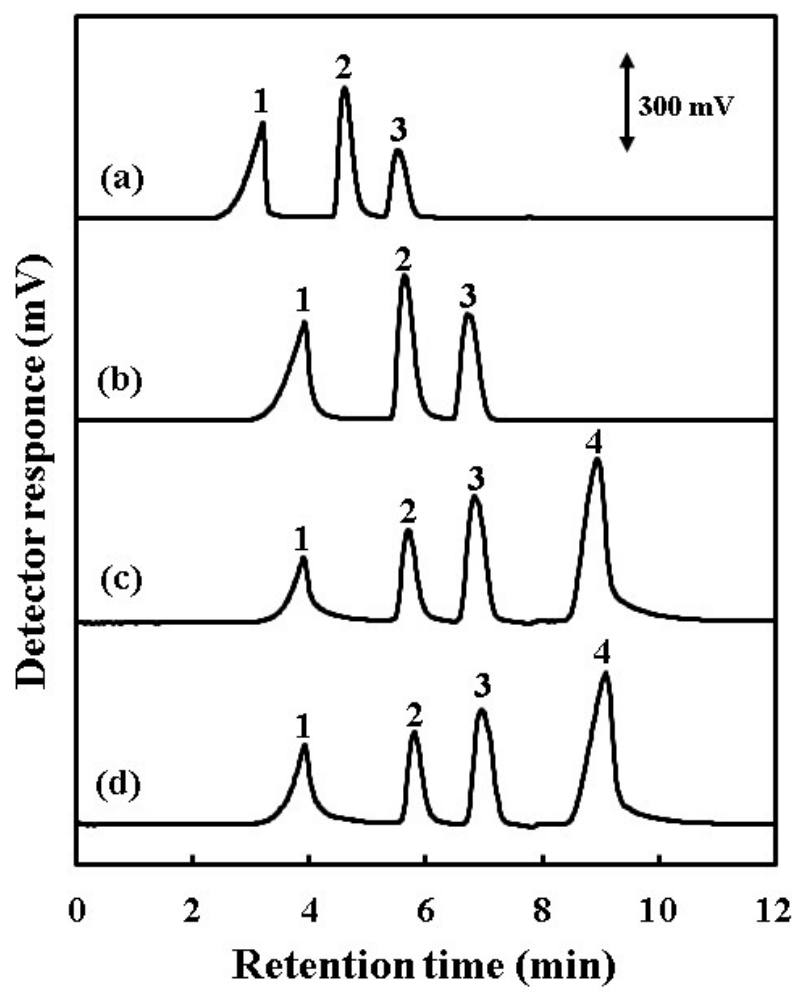

Figure 4. Chromatograms of (a) a mixture standard solution of phosphoric, silicic, boric and carbonic acids without conversion column, and the solution with conversion column in $(\mathbf{b}) \mathrm{H}^{+}$-form; (c) $\mathrm{Na}^{+}$-form and (d) $\mathrm{K}^{+}$-form. Condition: injected sample, a mixture solution of $10 \mathrm{mgP} \cdot \mathrm{L}^{-1}$, $10 \mathrm{mgSi} \cdot \mathrm{L}^{-1}, 100 \mathrm{mgB} \cdot \mathrm{L}^{-1}$ and $21 \mathrm{mgC} \cdot \mathrm{L}^{-1}$. Other chromatographic conditions are the same as for Figure 2. Peaks identification: 1, phosphoric acid; 2, silicic acid; 3, boric acid; 4, carbonic acid.

The durability of the sequence of the columns was investigated, resulting in good repeatability of retention time and detector response of the acids on the chromatographic runs repeated 20 times, as summarized in Table 1. 
Table 1. Relative standard deviations of the retention times and peak areas of the analyte acids (10 mg. $\mathrm{L}^{-1}$ as Si for silicic acid, $100 \mathrm{mg} \cdot \mathrm{L}^{-1}$ as B for boric acid and $21 \mathrm{mg} \cdot \mathrm{L}^{-1}$ as $\mathrm{C}$ for carbonic acid) on the 20th-repeated chromatographic runs.

\begin{tabular}{ccc}
\hline Acid & Retention Time (\%) & Peak Area (\%) \\
\hline Silicic acid & 1.03 & 3.11 \\
Boric acid & 1.55 & 3.40 \\
Carbonic acid & 0.39 & 3.08 \\
\hline
\end{tabular}

\subsection{Analytical Performance Using IEC with the C-CAD}

Under the optimized conditions, the analytical performance of this method were evaluated. The calibration curves in linear-coordinate plots of the analyte concentrations versus peak area were not linear. In chromatographic practice, the detector response for CAD typically follows a relationship:

$$
A=a C^{b}
$$

where $A$ is the peak area, $C$ is the analyte concentration, and $a$ and $b$ are constants depending on detection conditions such as droplet size, solute nature, flow rate and molar volatility [24]. Therefore, the calibration curves were plotted in a log-log fashion of the analyte concentrations versus peak area. The calibration curves of the analyte concentrations versus peak area were linear in the concentration range $0.5-10 \mathrm{mg} \cdot \mathrm{L}^{-1}$ as $\mathrm{Si}$ for silicic acid, $10-100 \mathrm{mg} \cdot \mathrm{L}^{-1}$ as B for boric acid and $1.3-21 \mathrm{mg} \cdot \mathrm{L}^{-1}$ as $\mathrm{C}$ for carbonic acid, as summarized in Table 2. While the responses of weak inorganic acids by insertion of conversion column was slightly changed, the linearity of calibration curves for silicic $\left(r^{2}=0.999\right)$ and boric $\left(r^{2}=0.998\right)$ acids without use of the conversion column were also good. The detection limits of weak inorganic acids based on three times the standard deviations of a lowest standard solution injected 7 times were also good.

Table 2. The linear ranges, the correlation coefficients $\left(r^{2}\right)$ of calibration curve, detection limits and recoveries for optimized IEC with the C-CAD of silicic, boric and carbonic acids.

\begin{tabular}{|c|c|c|c|c|}
\hline Acid & Linear Range $\left(\mathrm{mg} \cdot \mathrm{L}^{-1}\right)$ & $r^{2}$ & Detection Limit $\left(\mathrm{mg} \cdot \mathrm{L}^{-1}\right)$ & Recovery * (\%) (min.-max.) \\
\hline Silicic acid & $0.5-10$ & 0.996 & 0.03 & $101.4 \pm 2.7(98.2-104.6)$ \\
\hline Boric acid & $10-100$ & 0.998 & 0.40 & $99.3 \pm 3.7(94.3-103.5)$ \\
\hline Carbonic acid & $1.3-21$ & 0.993 & 0.08 & $98.4 \pm 4.0(92.2-102.8)$ \\
\hline
\end{tabular}

For the recovery test, the standard solutions at $5 \mathrm{mg} \cdot \mathrm{L}^{-1}$ as Si for silicic acid, $50 \mathrm{mg} \cdot \mathrm{L}^{-1}$ as $\mathrm{B}$ for boric acid and $13 \mathrm{mg} \cdot \mathrm{L}^{-1}$ as $\mathrm{C}$ for carbonic acid were added to the mineral water and hot spring water samples. The results of recoveries were very good, as summarized in Table 2. Typical chromatograms for mineral water and hot spring water samples using IEC connecting a conversion column with the C-CAD were shown in Figure 5. 


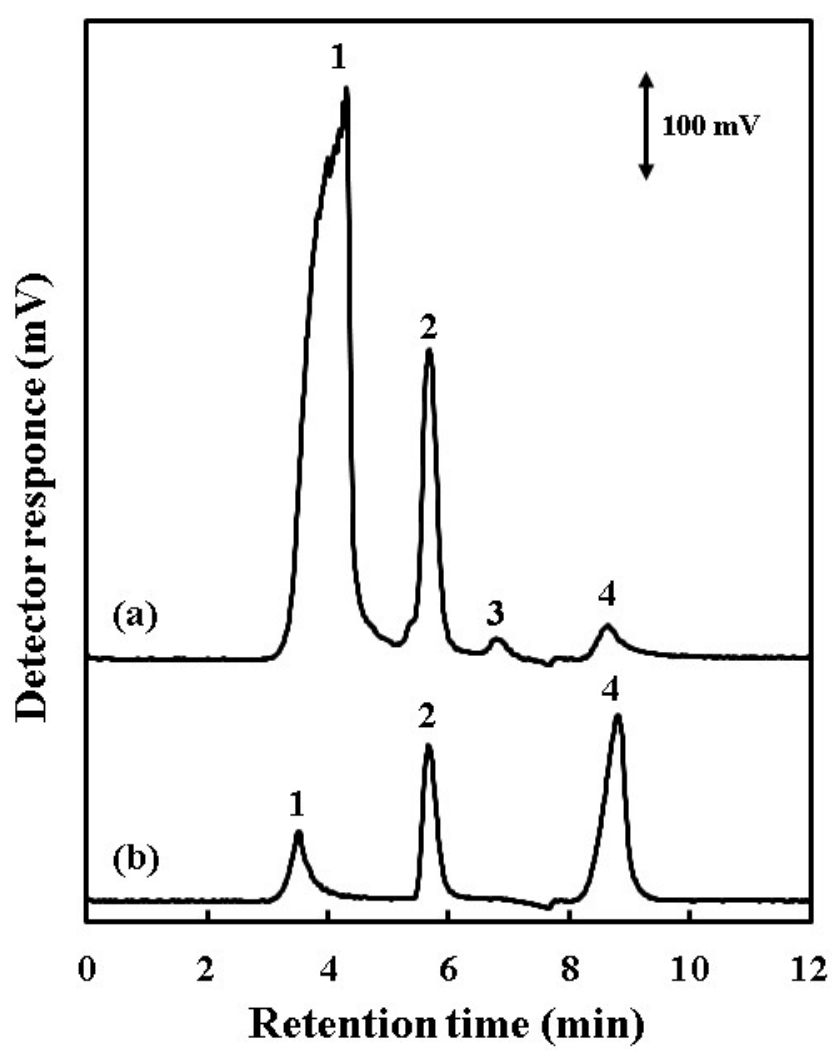

Figure 5. Typical chromatograms of (a) hot spring water (5-times diluted) and (b) drinking water (10-times diluted). Chromatographic conditions are the same as for Figure 2. Peaks identification: 1, phosphoric acid and strong acid anions; 2 , silicic acid; 3, boric acid; 4, carbonic acid.

\section{Conclusions}

Using a weakly acidic cation-exchange resin in $\mathrm{H}^{+}$-form and a pure-water-based eluent, the simple and simultaneous determination of silicic and boric acids by IEC with the C-CAD was achieved. By inserting the conversion column packed a strong acidic cation-exchange resin in $\mathrm{Na}^{+}$- or $\mathrm{K}^{+}$-form between the separation column and the detector, weak inorganic acids including carbonic acid in natural water by IEC with the C-CAD was accomplished. The effectiveness of the present methods for simultaneous determination for weak inorganic acids in natural water of river, hot spring and drinking water samples were successfully demonstrated without the specific chemical derivatization.

Acknowledgments: We thank the staff of Tosoh Corporation for their useful suggestions and providing the cation-exchange column used in this study.

Author Contributions: Yu Otsuka and Nobutake Nakatani performed the experimental work and wrote the paper. Takuya Takahashi and Masanobu Mori performed the initial experiments regarding the IEC with C-CAD for determination of silicic and boric acid. Daisuke Kozaki prepared the enhancement column. Kazuhiko Tanaka designed the experiment.

Conflicts of Interest: The authors declare no conflict of interest.

\section{References}

1. Subranabuan, V.; Ittekkot, V.; Unger, D.; Madhavan, N. Silicate Weathering in South Asian Tropical River Basins. In The Silicon Cycle: Human Perturbations and Impacts on Aquatic Systems; Ittekkot, V., Unger, D., Humborg, C., An, N.T., Eds.; Island Press: Washington DC, USA, 2006; pp. 3-12.

2. Davila, L.P.; Risbud, S.H.; Shackelford, J.F. Quartz and Silicas. In Ceramic and Glass Materials. Structure, Properties and Processing; Shackelford, J.F., Doremus, R.H., Eds.; Springer Scence+Business Media, LLC: New York, NY, USA, 2008; pp. 71-86. 
3. Park, H.; Schlesinger, W.H. Global biogeochemical cycle of boron. Global Biogeochem. Cycles 2002. [CrossRef]

4. Schlesinger, W.H. An Overview of the Carbon Cycle. In Soils and Global Change; Lal, R., Kimble, J., Levine, E., Stewart, B.A., Eds.; Lewis Publishers: Boca Raton, FL, USA, 1995; pp. 9-26.

5. Stumm, W.; Morgan, J.J. Aquatic Chemistry: Chemical Equilibria and Rates in Natural Waters, 3rd ed.; Wiley/Interscience: New York, NY, USA, 1996.

6. Eaton, A.D.; Clesceri, L.S.; Rice, E.W.; Greenberg, A.E. Standard Methods for the Examination of Water $\mathcal{E}$ Wastewater, 21st ed.; APHA-AWWA-WFE: Washington DC, USA, 2005.

7. Abe, K.; Watanabe, Y. Determination of silicate in seawater by inductivity coupled plasma atomic emission spectrometry. J. Oceanogr. 1992, 48, 283-292. [CrossRef]

8. Farhat, F.; Ahmad, F.; Arafat, H. Analytical techniques for boron quantification supporting desalination processes: A review. Desalination 2013, 310, 9-17. [CrossRef]

9. Fritz, J.; Gjerde, D.T. Ion-Exclusion Chromatography. In Ion Chromatography, 4th ed.; Wiley-VCH: Weinheim, Germany, 2009; pp. 207-237.

10. Li, H.-B.; Chen, F. Determination of silicate in water by ion exclusion chromatography with conductivity detection. J. Chromatogr. A 2000, 874, 143-147. [CrossRef]

11. Wilshire, J.P.; Brown, W.A. Determination of boric oxide by ion chromatography and ion chromatography exclusion. Anal. Chem. 1982, 54, 1647-1650. [CrossRef]

12. Tanaka, K.; Fritz, J.S. Determination of bicarbonate by ion-exclusion chromatography with ion-exchange enhancement of conductivity detection. Anal. Chem. 1987, 59, 708-712. [CrossRef]

13. Ikedo, M.; Mori, M.; Kurachi, K.; Hu, W.; Tanaka, K. Selective and simultaneous determination of phosphate and silicate ions in leaching process waters for ceramics glaze raw materials of natural origin by ion-exclusion chromatography coupled with UV-detection after postcolumn derivatization. Anal. Sci. 2006, 22, 117-121. [CrossRef] [PubMed]

14. Nakatani, N.; Kozaki, D.; Masuda, W.; Nakagoshi, N.; Hasebe, K.; Mori, M.; Tanaka, K. Simultaneous spectrophotometric determination of phosphate and silicate ions in river water by using ion-exclusion chromatographic separation and post-column derivatization. Anal. Chim. Acta 2008, 619, 110-114. [CrossRef] [PubMed]

15. Nakatani, N.; Masuda, W.; Kozaki, D.; Goto, R.; Nakagoshi, N.; Mori, M.; Hasebe, K.; Tanaka, K. Simultaneous spectrophotometric determination of orthophosphate and silicate ions in river water using ion-exclusion chromatography with an ascorbate solution as both eluent and reducing agent, followed by postcolumn derivatization with molybdate. Anal. Sci. 2009, 25, 379-383. [CrossRef] [PubMed]

16. Inoue, Y.; Date, Y. Determination of boron using ion-exclusion chromatography with postcolumn derivatization method. Bunseki Kagaku 1994, 43, 365-370. [CrossRef]

17. Vehovec, T.; Obreza, A. Review of operating principle and applications of the charged aerosol detector. J. Chromatogr. A 2010, 1217, 1549-1556. [CrossRef] [PubMed]

18. Ligor, M.; Studzińska, S.; Horna, A.; Buszewski, B. Corona-charged aerosol detection: An analytical approach. Crit. Rev. Anal. Chem. 2013, 43, 64-78. [CrossRef]

19. Magnusson, L.-E.; Risley, D.S.; Koropchak, J.A. Aerosol-based detectors for liquid chromatography. J. Chromatogr. A 2015, 1421, 68-81. [CrossRef] [PubMed]

20. Almeling, S.; Ilko, D.; Holzgrabe, U. Charged aerosol detection in pharmaceutical analysis. J. Pharm. Biomed. Anal. 2012, 69, 50-63. [CrossRef] [PubMed]

21. Crafts, C.; Bailey, B.; Plante, M.; Acworth, I. Evaluation of methods for the simultaneous analysis of cations and anions using HPLC with charged aerosol detection and a zwitterionic stationary phase. J. Chromatogr. Sci. 2009, 47, 534-539. [CrossRef] [PubMed]

22. Huang, Z.; Richards, M.A.; Zha, Y.; Francis, R.; Lozano, R.; Ruan, J. Determination of inorganic pharmaceutical counterions using hydrophilic interaction chromatography coupled with Corona ${ }^{\circledR}$ CAD detector. J. Pharm. Biomed. Anal. 2009, 50, 809-814. [CrossRef] [PubMed]

23. Zhang, K.; Dai, L.; Chetwyn, N.P. Simultaneous determination of positive and negative pharmaceutical counterions using mixed-mode chromatography coupled with charged aerosol detector. J. Chromatogr. A 2010, 1217, 5776-5784. [CrossRef] [PubMed] 
24. Mori, M.; Sagara, K.; Arai, K.; Nakatani, N.; Ohira, S.; Toda, K.; Itabashi, H.; Kozaki, D.; Sugo, Y.; Watanabe, S.; et al. Simultaneous analysis of silicon and boron dissolved in water by combination of electrodialytic salt removal and ion-exclusion chromatography with corona charged aerosol detection. J. Chromatogr. A 2016, 1431, 131-137. [CrossRef] [PubMed]

25. Tanaka, K. Study on water quality monitoring by advanced ion-exclusion chromatography. Bunseki Kagaku 2006, 55, 275-289. [CrossRef]

26. Nakatani, N.; Kozaki, D.; Mori, M.; Hasebe, K.; Nakagoshi, K.; Tanaka, K. Ion-exclusion/cation-exchange chromatography with dual detection of the conductivity and spectrophotometry for the simultaneous determination of common inorganic anionic species and cations in river and wastewater. Anal. Sci. 2011, 27, 499-504. [CrossRef] [PubMed]

27. Nakatani, N.; Kozaki, D.; Mori, M.; Tanaka, K. Recent progress and applications of ion-exclusion/ ion-exchange chromatography for simultaneous determination of inorganic anions and cations. Anal. Sci. 2012, 28, 845-852. [CrossRef] [PubMed]

28. Tanaka, K.; Ishizuka, T. Elution behavior of acids in ion-exclusion chromatography using a cation-exchange resin. J. Chromatogr. 1979, 174, 153-157. [CrossRef]

29. Glòd, B.K. Ion exclusion chromatography: Parameters influencing retention. Neurochem. Res. 1997, 22, 1237-1248. [CrossRef] [PubMed]

30. Tanaka, K.; Ohta, K.; Fritz, J.S.; Matsushita, S.; Miyanaga, A. Simultaneous ion-exclusion chromatography -cation-exchange chromatography with conductimetric detection of anions and cations in acid rain waters. J. Chromatogr. A 1994, 671, 239-248. [CrossRef]

31. Mori, M.; Itabashi, H.; Helaleh, M.I.H.; Kaczmarski, K.; Glòd, B.K.; Kowalska, T.; Xu, Q.; Ikedo, M.; Hu, W.; Tanaka, K. Vacancy ion-exclusion chromatography of inorganic acids on a weakly acidic cation-exchange resin column. J. Chromatogr. A 2006, 1118, 41-45. [CrossRef] [PubMed]

32. Mori, M.; Tanaka, K.; Taoda, H.; Ikedo, M.; Hu, W. Ion-exclusion chromatography of silicate ion in sea and river water samples by an ion-exchange enhancement of conductivity detection. Bunseki Kagaku 2004, 53, 1481-1486. [CrossRef]

33. Mori, M.; Ikedo, M.; Hu, W.; Helaleh, M.I.H.; Xu, Q.; Itabashi, H.; Tanaka, K. High-speed ion-exclusion chromatography of dissolved carbon dioxide on a small weakly acidic cation-exchange resin column with ion-exchange enhancement columns of conductivity detection. J. Chromatogr. A 2005, 1092, 250-253. [CrossRef] [PubMed]

34. Mori, M.; Itabashi, H.; Ikedo, M.; Tanaka, K. Ion-exclusion chromatography with the direct UV detection of non-absorbing inorganic cations using an anion-exchange conversion column in the iodide-form. Talanta 2006, 70, 174-177. [CrossRef] [PubMed]

35. Karu, N.; Dicinoski, G.W.; Haddad, P.R. Use of suppressors for signal enhancement of weakly-acidic analytes in ion chromatography with universal detection methods. Trends Anal. Chem. 2012, 40, 119-132. [CrossRef]

36. Morris, J.; Fritz, J.S. Eluent modifiers for the liquid chromatographic separation of carboxylic acids using conductivity detection. Anal. Chem. 1994, 66, 2390-2396. [CrossRef]

(C) 2016 by the authors; licensee MDPI, Basel, Switzerland. This article is an open access article distributed under the terms and conditions of the Creative Commons by Attribution (CC-BY) license (http://creativecommons.org/licenses/by/4.0/). 